\title{
Recording of taste cell receptor potential from keratin-removed rat tongue
}

\author{
Toshihide Sato and Yukio Okada \\ Department of Physiology (Chief: Prof. Toshihide Sato), Nagasaki University \\ School of Dentistry, 7-1 Sakamoto-machi, Nagasaki 852, Japan
}

[Accepted for publication: March 29, 1983]

Key words: tongue / rat taste cell / receptor potential / keratinized layer / fungiform papilla

A taste cell responds to taste stimuli with a depolarizing or hyperpolarizing receptor potential. This potential has been recorded intracellularly from several species of the vertebrate, such as rat, hamster, frog, mudpuppy and catfish ${ }^{1)}$. The tongue surface of mammals is ordinarily covered with a hard keratin layer except for taste pore portions of the lingual papillae. When a microelectrode is inserted into a taste cell in the mammalian tongue, it must be advanced through the taste pore of a few micra in diameter. If not, the tip of the microelectrode will be broken easily ${ }^{2,3}$. Therefore, if the keratinized layer covering the dorsal tongue epithelium is removed chemically or mechanically without damaging the morphological and physiological properties of taste cells, the penetration of a microelectrode into a taste cell becomes easier because it will be possible to advance the microelectrode tip from within and without the taste pore.

The purpose of the present experiment was to examine whether or not the receptor potential recorded intracellularly from the taste cell after the keratinized layer was removed from the rat dorsal tongue surface showed a normal waveform.

\section{Materials and Methods}

Four female Sprague-Dawley rats weighing $210-310 \mathrm{~g}$ were used. The animals were anesthetized with urethane given intraperitoneally in a dose of $1 \mathrm{~g} / \mathrm{kg}$. The hypoglossal nerves were severed bilaterally to remove the spontaneous tongue movement.
When recording gustatory neural responses, the chorda tympani nerve on either side was exposed and cut near the bulla. The chorda tympani was suspended with a monopolar silver wire electrode of $0.2 \mathrm{~mm}$ dia. and immersed in liquid paraffin. Neural impulses amplified were recorded on a pen-recorder through an integrator of $1 \mathrm{sec}$ time constant. Four basic taste solutions of $0.5 \mathrm{M} \mathrm{NaCl}$, $0.02 \mathrm{M}$ quinine- $\mathrm{HCl}$ (Q-HCl), $0.01 \mathrm{M} \mathrm{HCl}$ and $0.5 \mathrm{M}$ sucrose, prepared with distilled water, were applied at a flow rate of $0.8 \mathrm{ml} /$ sec to the tongue which had been adapted beforehand to distilled water. Following stimulation, the tongue was rinsed with distilled water.

Intracellular recordings were made from taste cells in the taste bud of the fungiform papillae using a microelectrode technique. Details of the recording procedure have been reported $^{2-5)}$. In the microelectrode experiments, distilled water as an adapting solution was continuously flowed to the tongue at a rate of $1.4 \mathrm{ml} / \mathrm{min}$ by using a simple gustatory stimulator ${ }^{3,4)}$ and a taste solution was delivered following stoppage of the water.

In the test experiments, the keratin layer lying at the dorsal tongue surface was carefully peeled with a pair of fine forceps after distilled water had been flowed over the intact tongue for about $5 \mathrm{~min}$.

The keratin-removed tongue surface was observed with light and scanning electron microscopes. The histological preparations were prepared according to routine procedures.

All experiments were performed at a room 
temperature of $25-28^{\circ} \mathrm{C}$.

\section{Results and Discussion}

Comparison of taste sensitivities in the normal and keratin-removed rat tongues was first performed by recording the gustatory responses of the chorda tympani nerve. Figure 1 shows examples of integrated chorda tympani nerve response elicited by application of the four basic taste stimuli to the normal (A) and keratin-removed tongue (B). In obtaining record $\mathrm{B}$, the keratinized layer was removed from over more than the anterior two-thirds of the dorsal tongue surface, which is innervated by the chorda tympani. As seen in Fig. 1B, the magnitude of the integrated neural response to $\mathrm{NaCl}$ did not change, but those to Q-HCl, $\mathrm{HCl}$ and sucrose were reduced to 40,40 and $72 \%$ of the respective controls. Similar values were obtained in other preparations. Rise time of the integrated neural response, defined as the time to reach its peak after the response onset, became longer with each taste stimulation of the keratin-removed tongue.

In the case of intracellular recordings, the keratin layer was very carefully removed only from a small area of the tongue containing a few fungiform papillae. In Fig. 2 is shown an example of receptor potentials in taste cells in the normal (A) and keratin-removed tongue (B). The amplitude of resting potential was $-50 \pm 3 \mathrm{mV}$ (mean $\pm \mathrm{SE}, \mathrm{n}=22$ ) in the taste cells of the control tongue and $-44 \pm 3 \mathrm{mV}(\mathrm{n}=11)$ in the taste cells of the test tongue. There was no significant difference between these values $(p>0.05)$. The rise time and magnitude of receptor potentials obtained from the control and test cells are tabulated in Table 1. With each taste stimulus no significant difference in the peak time was found between the taste cells in two kinds of tongues $(p>0.05)$. Also, the magnitude of receptor potentials elicited by each stimulus did not differ between the control and test tongue $(p>0.05)$. These lines of evidence suggest that a careful removal of the keratinized layer covering the papilla surface keeps the taste cell function normal. The small discrepancy between gustatory neural responses in the normal and keratin-removed tongue (Fig. 1) is due to the possibility that a small percentage of the

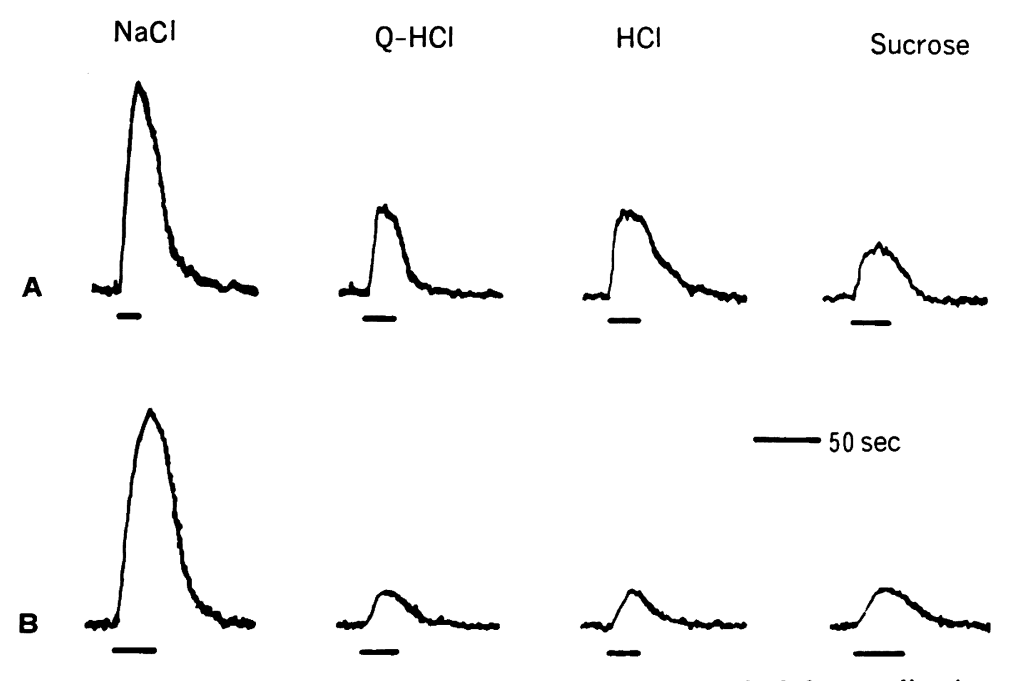

Fig. 1 Integrated chorda tympani nerve responses evoked by application of four basic taste stimuli to the normal (A) and keratin-removed tongue (B). The two records A and B were obtained from one and the same nerve of a rat. Horizontal bars in this and the next figure indicate the duration of stimulus application. Taste stimuli : $0.5 \mathrm{M}$ $\mathrm{NaCl}, 0.02 \mathrm{M} \mathrm{Q}-\mathrm{HCl}, 0.01 \mathrm{M} \mathrm{HCl}$ and $0.5 \mathrm{M}$ sucrose. 
$\mathrm{NaCl}$

Q- $\mathrm{HCl}$

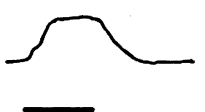

A
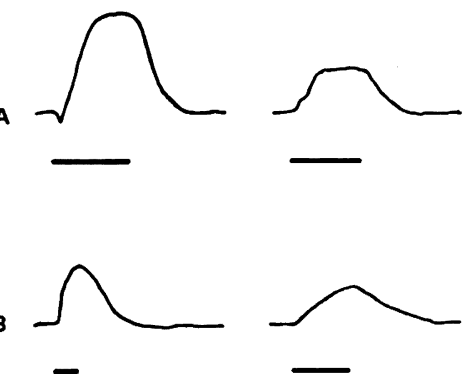

$\mathrm{HCl}$
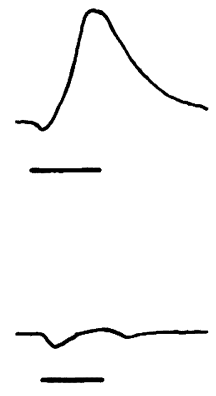

Sucrose
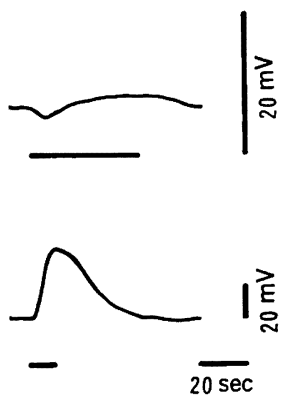

Fig. 2 Intracellularly recorded receptor potentials of taste cells in the normal (A) and keratin-removed rat tongue (B) in response to four basic taste stimuli. The two records $A$ and $B$ were obtained from two different taste cells. The tongue surface was adapted to distilled water. Taste stimuli: $0.5 \mathrm{M} \mathrm{NaCl}, 0.02 \mathrm{M}$ Q-HCl, $0.01 \mathrm{M}$ $\mathrm{HCl}$ and $0.5 \mathrm{M}$ sucrose.

Table 1 The rise time and amplitude of receptor potentials of taste cells in response to four basic taste stimuli in the normal and keratin-removed tongues

\begin{tabular}{lrrrrrrr}
\hline \multirow{2}{*}{ Taste stimuli } & \multicolumn{2}{c}{ Rise time $(\mathrm{sec})$} & & \multicolumn{2}{c}{ Amplitude $(\mathrm{mV})$} \\
\cline { 2 - 3 } & Control cells $(n)$ & Test cells $(n)$ & & Control cells $(n)$ & Test cells $(n)$ \\
\hline $0.5 \mathrm{M} \mathrm{NaCl}$ & $9.7 \pm 1.5(18)$ & $7.2 \pm 2.4(11)$ & & $31.3 \pm 3.3(19)$ & $26.4 \pm 4.8(11)$ \\
$0.02 \mathrm{M} \mathrm{Q}-\mathrm{HCl}$ & $11.7 \pm 1.5(18)$ & $12.6 \pm 2.2$ & $(8)$ & & $16.2 \pm 5.3(19)$ & $18.8 \pm 5.4$ & $(8)$ \\
$0.01 \mathrm{M} \mathrm{HCl}$ & $9.7 \pm 1.4(18)$ & $12.5 \pm 2.2$ & $(7)$ & & $12.6 \pm 4.0(19)$ & $13.1 \pm 3.7$ & $(7)$ \\
$0.5 \mathrm{M}$ sucrose & $10.3 \pm 3.9(16)$ & $11.8 \pm 2.6$ & $(7)$ & & $10.3 \pm 4.7(19)$ & $21.9 \pm 11.1$ & $(7)$ \\
\hline
\end{tabular}

Each value is mean $\pm \mathrm{SE}$. The sign $n$ means the number of taste cells sampled. Control cells were obtained from the normal tongue and test cells from the keratin-removed tongue.

taste cells were damaged while peeling the keratin layer of a large portion of the tongue surface.

Observations with light and scanning electron microscopes indicated that the keratin layer covering the epithelium of fungiform papillae was removed clearly and that there was no sign of damage to the taste pore region.

The present experiment suggests that keratin-removed fungiform papillae are a useful material for microelectrode study of rat taste cells.

\section{References}

1) Sato, T.: Recent advances in the physiology of taste cells. Prog. Neurobiol. 14: 25-67,
1980.

2) Ozeki, M. and Sato, M.: Response of gustatory cells in the tongue of rat to stimuli representing four taste qualities. Comp. Biochem. Physiol. 41A: 391-407, 1972.

3) Sato, T. and Beidler, L. M.: The response characteristics of rat taste cells to four basic taste stimuli. Comp. Biochem. Physiol. 73A: $1-10,1982$.

4) Sato, T. and Beidler, L. M.: Membrane resistance change of the frog taste cells in response to water and NaCl. J. Gen. Physiol. 66: 735-763, 1975.

5) Sato, T. and Beidler, L. M.: Dependence of gustatory neural response on depolarizing and hyperpolarizing receptor potentials of taste cells in the rat. Comp. Biochem. Physiol. 75A : 131-137, 1983. 